ppi $201502 Z U 4645$

Esta publicación cientifica en formato digital es continuidad de la revista impresa ISSN-Versión Impresa 0798-1406 / ISSN-Versión on line 2542-3185Depósito legal pp

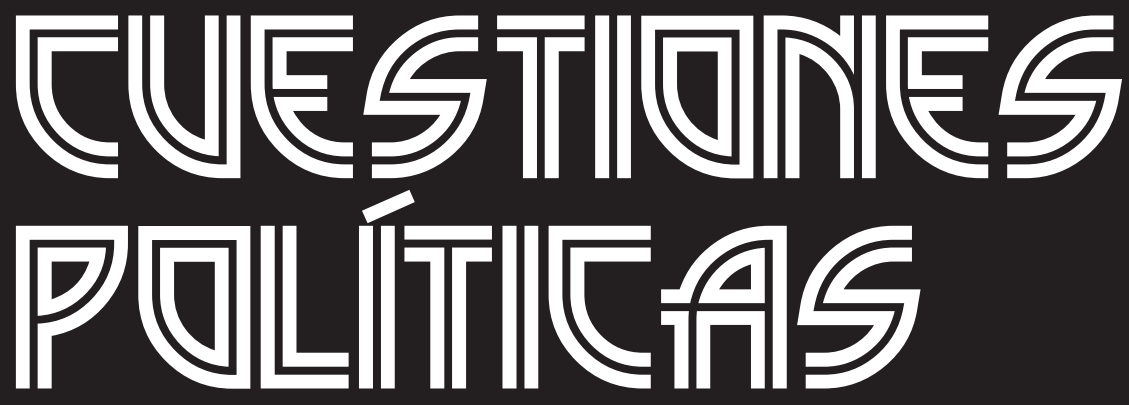

Instituto de Estudios Políticos y Derecho Público "Dr. Humberto J. La Roche' de la Facultad de Ciencias Jurídicas y Políticas de la Universidad del Zulia Maracaibo, Venezuela
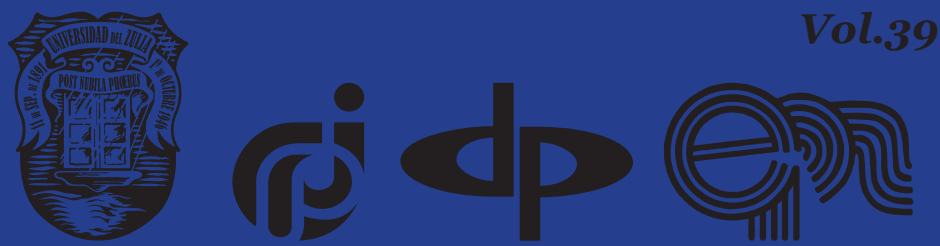


\title{
Historia y actualidad del Régimen Legal del Sistema Presupuestario Público Venezolano
}

\author{
DOI: https://doi.org/10.46398/cuestpol.3968.31
}

\author{
Eduardo J. Millano *
}

\section{Resumen}

El estado como estructura jurídico política de gran importancia para la sociedad, requiere de instrumentos sobre planificación y control para mantener sus fines esenciales para el cual fue creado, entre esos instrumentos se encuentra el presupuesto público, el cual es una herramienta administrativa así como operativa para la toma de decisiones del gobierno, con el fin de lograr la consecución o fines del estado a través de los planes de desarrollo y en fin, poder impulsar para propiciar la satisfacción de necesidades básicas de la población. La presente investigación tiene como finalidad desarrollar los aspectos más relevantes de la historia y actualidad del régimen legal del sistema presupuestario venezolano, donde se enfatiza que se cuenta con un extenso material entre documentos y libros, los cuales puntalmente se han seleccionado para limitar con los aspectos más relevantes. Así mismo es importante señalar que este estudio se limita a la evolución histórico doctrinario mas no así a su disertación en relación con sus fases, ejecución y evaluación. Para la investigación fue utilizada como instrumento de recolección de datos la observación directa de leyes, portales oficiales del estado y doctrina venezolana.

Palabras clave: Presupuesto público; estado venezolano; historia jurídica-institucional; régimen legal; Venezuela.

\footnotetext{
Abogado, Lcdo. en Contaduría Pública. Catedrático Venezolano del Derecho Público. Profesor de la Universidad del Zulia (LUZ), en las Cátedras Derecho Tributario y Practica Civil-Mercantil. Universidad Nacional Abierta (UNA) y de la Universidad Dr. Rafael Belloso Chacín (URBE), en las materias: Derecho Público, Derecho Administrativo, Finanzas Publicas, Derecho Financiero, Tributario y Contable. Miembro de Número de la Academia de las Ciencias Contables del Estado Zulia. ORCID ID: https://orcid.org/oooo-0oo2-8288-9530. Email: eduardojmv20@gmail.com
} 


\title{
492 \\ Eduardo J. Millano \\ Historia y actualidad del Régimen Legal del Sistema Presupuestario Público Venezolano \\ History and current affairs of the Legal Regime of the Venezuelan Public Budget System
}

\begin{abstract}
The state as a political structure of great importance for society, requires planning and control instruments to maintain its essential fines for which it was created, among these instruments is the public budget, which is an administrative as well as an operational tool for decision-making by the government, in order to achieve or obtain fines from the state through the development plans and, finally, to be able to promote the satisfaction of the basic needs of the population. The purpose of this research is to develop the most relevant aspects of the history and current affairs of the legal regime of the Venezuelan budgetary system, where it is emphasized that there is extensive material between documents and books, which have occasionally been selected to limit the most important aspects. relevant. Likewise, it is important to point out that this study is limited to the doctrinal historical evolution, but not to its dissertation in relation to its phases, execution, and evaluation. For the investigation, direct observation of laws, official state portals and Venezuelan doctrine was detected as a data collection instrument.
\end{abstract}

Keywords: Public budget; Venezuelan state; legal-institutional history; legal regime; Venezuela.

\section{Introducción}

El conjunto de elementos administrativos que hacen posible la captación y aplicación de recursos para la consecución eficiente y eficaz de objetivos, así como metas de la gestión gubernamental, se ha denominado administración financiera del sector público (Paredes, 2011); en este sentido, el presupuesto público constituye uno de los compendios empleados de que se vale la acción del gobierno para alcanzar sus metas, fines y objetivos. Por lo tanto, la obtención de ingresos, la ejecución de gastos, el financiamiento para cubrir déficit y la inversión de excedentes de liquidez, constituyen el proceso de trabajo que se ha denominado administración financiera pública.

Esta investigación no pretende realizar estudios comparativos entre instrumentos plurianuales de presupuesto, ni tampoco el análisis de sus partidas o la magnitud de los gastos en relación con inversión de sus ingresos. La misma se limitará al estudio histórico normativo del sistema presupuestario, su evolución como institución jurídica contable y los avances o retrocesos en la política venezolana de estos últimos años de acuerdo con el periodo constitucional del último presidente electo para la fecha que se escribe este trabajo: Nicolas Maduro Moros. 


\section{Fundamentación Teórica: Generalidades del presupuesto público}

El tema del presupuesto público y del derecho presupuestario se ha enmarcado como una rama del derecho financiero junto al tributario, los cuales han realizados aportes pertinentes que entre los que destacan los trabajos de (Duverger, 1980), el cual expresa que el presupuesto público se enmarca en actos de previsión y además de autorización de ingresos, así como los gastos.

Por otro lado, (Fariñas, 1986) afirma que el presupuesto público es un documento que tiene forma especial de ley y en el cual se estiman los ingresos disponibles en una entidad pública durante un periodo futuro y determinado, generalmente un año, se autorizan los gastos que esta entidad pública pueda efectuar hasta cierto límite en ese periodo, a los efectos de cumplir con una finalidad en el especificada, en el sentido de que constituye a la expresión contable del plan de la nación en aquellos aspectos que exigen por parte del sector público, captar y asignar recursos conducentes al cumplimiento de las metas del desarrollo económico, social e institucional del país.

Es importante hacer mención de la visión jurídico-contable que se tiene del instrumento, por cuanto el mismo debe cumplir con diferentes niveles y procesos para su aprobación por el poder legislativo, se constituyen una ley especial en él se reflejan las partidas monetarias de ingresos y gastos de la nación en un periodo determinado.

Asimismo, es pertinente señalar lo relacionado al concepto sobre el derecho presupuestario, el cual de acuerdo con (Fariñas, 1986) está formado por el conjunto de normas referidas a la confección, discusión, aprobación y fiscalización del presupuesto. Esta doctrina es una rama del derecho financiero sumamente importante, por cuanto se refiere a la vida misma del estado como tal.

\section{La génesis presupuestaria}

En los antiguos imperios que surgieron como Egipto y Babilonia se conformaron gobiernos centralizados, con administraciones dotadas de una organización capaz de emprender grandes obras materiales, donde la programación de gastos en relación con los ingresos no podía estar ausente. De igual manera ocurrió en Roma donde se logró implementar una verdadera tributación con el perfeccionamiento del censo, pero ni en la república ni en el imperio se establecieron presupuestos en el sentido moderno de la expresión (Rachadell, 1993).

El presupuesto ha tenido importancia desde los inicios de la humanidad, se puede evidenciar en las diferentes civilizaciones humanas tuvieron que 
implementar elementos los cuales ayudaron para predecir cuales serían las expectativas para el próximo año, quizá expresando de una manera más sencilla y no con la tecnicidad o importancia jurídicas-contable que amerita.

Se afirman que es en la ciudad de Génova, Italia, en el siglo XIV, donde se empieza a reflexionar sobre el manejo del presupuesto con la familia Massari, quien, en el año 1340, propone una forma de asignación y control de recursos; en 1494, el fraile Luca Paccioli, sistematiza la partida doble, lo cual da pie al surgimiento de lo que se conoce como contabilidad. Dos siglos más tarde, el monje Benedictino Ángelo Pietra, se ubica como el primer autor que se preocupa por la previsión de los ingresos y los gastos ocurridos. Un siglo después, Lodovico Flori, se convierte en el primero en escribir sobre presupuesto (1636).

En relación con el origen del término Presupuesto (Andara, 2012) se refiere a la palabra budget, derivada al parecer de una antigua palabra denominada bouget, la cual significaba bolsa o cartera, se le aplicó durante mucho tiempo a la gran cartera de cuero en que el tesorero del rey en Inglaterra, más tarde The Chancellor of the Exchequer, llevaba los documentos financieros al parlamento. La frase perdió su significado, pero la expresión opening the budget llegó a convertirse en el lenguaje oficial parlamentario para indicar la apertura de la discusión presupuestaria en Inglaterra.

Es, en Inglaterra en el siglo XVIII, donde surge el presupuesto como parte de un proceso como medida de ejecución y control, el cual tiene su origen en el ramo gubernamental con el llamado presupuestos por programas para el control de los gastos del reino, el cual el parlamento examinaría y discutiría anualmente, esto a la par del desarrollo de la revolución industrial. En 1820 Francia adopta el sistema en el ramo de gobierno y un año más tarde Estados Unidos lo trae a América como medida de control del gasto público, donde el principal objeto iba encaminado al eficiente funcionamiento de las actividades.

El establecimiento del estado de derecho y el surgimiento del derecho presupuestario se producen en Europa trayendo como consecuencia que este último sometido al estado derecho el mismo se discutiera en las cámaras y se estableciera principios o garantías para lo que no estuviere establecido en la Ley o Carta Magna o como se le conoció en Inglaterra el Bill of Rights no pudiera ser cobrado al ciudadano.

Puede observarse que el presupuesto ha sido resultado político de luchas por la supremacía libradas entre el soberano y el representante del pueblo. Estos últimos consiguieron, primero, hacer admitir al rey que ningún impuesto podía ser establecido si el consentimiento de los representantes del pueblo y, segundo, controlar el empleo del fondo que había votado, o sea, los gastos públicos (Villegas, 1975). 


\section{El presupuesto en Venezuela: consideraciones históricas y jurídicas}

Antes deiniciar con el estudio documental sobrela historia presupuestaria en Venezuela, se hace necesario explicar brevemente lo que se conoce o se entiende como hacienda pública, por cuanto, en la mayoría de los textos y según los diferentes autores, se utilizan expresiones, tales como; hacienda o finanzas públicas, cuando se refieren al régimen jurídico del patrimonio del estado. Para (Rodríguez, 2014) se puede entender por hacienda pública el conjunto de bienes, ingresos y deudas que forman el activo y el pasivo de la nación, así como todos los demás bienes y rentas cuya administración corresponde al poder nacional.

Es lógico e importante señalar que el ramo y estudio de la hacienda pública tuvo un interés por los gobernantes por cuanto allí se concentraban los haberes del estado. La reglamentación, origen y desarrollo de esta es extensa y basta, pero se podría sintetizar con el aporte que realizo el libertador Simón Bolívar con el decreto del 8 de marzo de 1827, en el cual se estructuran las bases económicas del país en los primeros años de vida republicana, en él se establecían claramente el desarrollo de instituciones como una dirección de rentas y un tribunal de contaduría de cuentas entre otras importantes para el desarrollo de la nación.

Del mismo modo, (Cabrera; 1988) expresa que, iniciada la colonización de Venezuela, con el arribo de los Welser en 1528 por un lado, y por el otro con la fundación de la ciudad de Coro en 1529, se organiza la estructura administrativa. Así mismo se realizan los registros de las cuentas de la real hacienda a cargo de oficiales reales en calidad de factor veedor, tesorero y contador, con lo cual se ponen en práctica los primeros procedimientos de control fiscal en lo concerniente al resguardo de los recursos del monarca.

Como se mencionó anteriormente, muchos han sido los instrumentos normativos para el resguardo de los recursos fiscales, al decreto del 8 de marzo de 1827 se le realizaron algunas reformas y estuvo vigente hasta el año 1830, luego le suceden la ley del 28 de mayo de 1837, el decreto del 15 de octubre de 1856 y el del 24 de junio de 1858, la Ley Orgánica del Tribunal de Cuentas del 6 de junio de 1860, el Código de Hacienda de 1873 y las sucesivas reformas a este último instrumento jurídico de ocurridas en 1884 y 1899 (Rodríguez, 2014).

En fecha 31 de mayo de 1899, bajo el gobierno del general Ignacio Andrade, se pone en vigencia un nuevo Código de Hacienda, el cual deroga al anterior aprobado en 1873 y que contempla varias actividades de la hacienda pública referidas al control de los ingresos, egresos y al funcionamiento administrativo del estado. Allí comienza por definirse lo que se entiende por hacienda nacional, igualmente se establecía que la centralización de todos los datos e informaciones relativas a ella serian ubicados en un organismo 
denominado la Contaduría General. Se incorporan definiciones referidas a los bienes nacionales, del fisco, funciones y atribuciones del ministro de hacienda, normativas relativas a la recaudación, entre otras.

Posteriormente, en el año 1912, se aprueba un nuevo Código de Hacienda que repite gran parte de las atribuciones y alcances del anterior. El 4 de junio de 1918 se aprueba la Ley Orgánica de la Hacienda Nacional, instrumento jurídico impulsado por el Doctor Román Cárdenas, ministro de hacienda desde 1913, quien había propuesto un conjunto de reformas hacendísticas en procura de mejorar los mecanismos de obtención de la renta, administración de los recursos estatales y elevar la eficiencia en el funcionamiento del despacho ministerial a su cargo. Esta ley deroga el Código de Hacienda de 1912 y les da una nueva dimensión jurídica y política a las actividades hacendísticas.

En este aspecto es importante destacar que de acuerdo con Salcedo (1979) citado por Rodríguez:

Con Gómez fue importante la labor-1914-1918- de su ministro Román Cárdenas, reorganizador de la administración de los ingresos públicos, ya que la Ley Orgánica de la Hacienda Nacional -1918- contiene lo fundamental de la reforma de la reforma cumplida: creación de la renta interna, unidad del tesoro, declaración obligatoria de los impuestos, normas para el presupuesto, inicio de la contabilidad nacional y la reorganización de los tribunales especializados (2014: 393).

Entre los años 1926 y 1928, se aprueban nuevas leyes orgánicas que reforman algunos aspectos de las anteriores, pero en lo sustancial mantienen la misma orientación de las precedentes. Por último, se sanciona la Ley Orgánica de la Hacienda Nacional en 1934, y ratifica el carácter dependiente de los órganos de fiscalización y examen en relación con el poder ejecutivo como una limitante del ejercicio del estudio preventivo y correctivo del gasto fiscal. Criterio este que se mantuvo hasta 1938, cuando se procede a crear la Contraloría General de la Nación dentro de la Ley Orgánica de Hacienda, otorgándole un sentido independiente con respecto al ejecutivo.

De tal manera, la Ley Orgánica de la Hacienda Pública Nacional se promulga el 15 de julio de 1938 y en su título VI establece la creación de la que para ese entonces se llamó la Contraloría General de la Nación, señalando expresamente en su artículo 149:

La fiscalización suprema de todos los ingresos y egresos del Tesoro Nacional, así como la centralización, el examen y el control de todas las cuentas y operaciones fiscales y de bienes nacionales, inclusive materiales y efectos adquiridos por oficinas nacionales, correrán a cargo de un organismo administrativo autónomo, que se denominara Contraloría General de la Nación (Cabrera, 1988: 26).

Dicha ley fue objeto de otra reforma en fecha 15 de julio de 1948, estando vigente hasta el día 11 de julio de 1974, cuando fue modificada 
sustancialmente con la aprobación de la Ley Orgánica de la Contraloría General de la República, en fecha 18 de diciembre de 1974, la cual entro en vigor a partir del 6 de enero de 1975 y que vino a derogar la Ley Orgánica de la Hacienda Pública Nacional en los aspectos referentes a esta materia.

Por otra parte, muchas de las disposiciones de la Ley Orgánica de la Hacienda Pública Nacional, en el aspecto presupuestario fueron derogadas por la Ley Orgánica de Régimen Presupuestario (1976). Igualmente, la Ley Orgánica de Contraloría General de la República (1975), derogó las disposiciones relacionadas con el control fiscal sobre la ejecución del presupuesto. Igualmente, lo referente a la tesorería nacional y el sistema de crédito público fue derogado por la Ley Orgánica de la Administración Financiera del Sector Publico (2006).

Así mismo en Venezuela se crea en 1941, el Consejo Nacional de Presupuesto. Hasta 1962 se formula el presupuesto de ingresos por ramos de origen y el de gasto de acuerdo con su naturaleza u objeto (presupuesto tradicional), por cuanto, para este año se elaboró un instrumento por programas que se presentó como documento anexo a la Ley de Presupuesto.

Por otro lado, (Esteves, 2005) expresa que hasta 1941, el presupuesto lo elaboraba el ministro de hacienda tomando en cuenta los presupuestos parciales de ministerios y departamentos. Luego a partir de ese año, se creó el Consejo Nacional de Presupuesto que era un organismo extraño por cuanto había representantes del congreso nacional, y al mismo tiempo, el congreso tenía que aprobar ese presupuesto: "pero luego se subsano esa irregularidad, cuando se creó la dirección general del presupuesto en 1948", más tarde denominada Dirección Nacional de Presupuesto, organismo dependiente de del ministerio de hacienda, cuyo primer director fue el doctor Héctor Hurtado.

\section{Marco jurídico normativo vigente del sistema presupuestario: avances y retrocesos Jurídicos-Políticos}

A partir del año 1971, se modifica el sistema presupuestario tradicional, es decir se le dio carácter de ley a un documento que durante nueve (9) años se estuvo presentando como anexo. No obstante, no existía un instrumento legal que normara de manera específica, el proceso presupuestario en el sector público. Para llenar este vacío legal, en 1976 se promulga la Ley Orgánica de Régimen Presupuestario, la cual fue reformada parcialmente en varias oportunidades.

En 1978, con la puesta en vigencia de la Ley Orgánica de Régimen Presupuestario, se crea la Oficina Central de Presupuesto como organismo rector del sistema presupuestario. Sin embargo, la referida depende de la presidencia de la república. Siendo el ministerio de hacienda hoy finanzas, 
Eduardo J. Millano
498 Historia y actualidad del Régimen Legal del Sistema Presupuestario Público Venezolano

el responsable de presentar el presupuesto general de recursos y egresos ante el congreso de Venezuela.

Diversos autores señalan que a finales del siglo XIX y comienzos del siglo XX, existían limitaciones en lo referente a la eficacia y disciplina de la hacienda pública nacional, Esta indisciplina administrativa es un producto no solo de la debilidad económica, sino de la debilidad política de la sociedad venezolana, que concurría para reducir la capacidad fiscal del Estado Venezolano del siglo XIX y comienzos del presente.

De allí que, desde hace algún tiempo, debido a la ausencia o la falta de integración entre las diferentes leyes que han recogido la administración de la hacienda pública en Venezuela, ha sido preocupación de muchos gobernantes la modernización de la administración financiera del sector público, con el fin de lograr una eficiente gestión fiscal.

Para ello han sido dictadas numerosas disposiciones con el objetivo de regular directamente el sistema presupuestario, en los ámbitos nacional, estatal o municipal. Entre ellas se pueden mencionar:

- Ley Orgánica de Régimen Presupuestario, aprobada en 1976, con la cual se le da una base sólida al principio de la programación y se crean los diferentes mecanismos a fin de vincular los presupuestos públicos con los planes de la nación, cuando señalaba en su artículo 2: Los presupuestos públicos expresan el plan de la nación en aquellos aspectos que exigen por parte del sector público, captar y asignar recursos dirigidos al cumplimiento de las metas de desarrollo económico, social e institucional del país.

- Ley Orgánica de Administración Financiera del Sector Publico (2000) (LOAFSP), para ser aplicada a partir de la elaboración del presupuesto 2002, derogó la Ley Orgánica de Régimen Presupuestario, Ley Orgánica de Crédito Público, algunas disposiciones de la ley Orgánica de la Hacienda Pública Nacional, en lo que al presupuesto se refiere. En el título II, artículo 9 de la referida ley se trata lo relativo al sistema presupuestario, el cual está integrado por el conjunto de principios, órganos, normas y procedimientos que rigen el proceso presupuestario de los entes órganos del sector público. De igual manera, en la referida ley en su artículo 10, se establece que los presupuestos públicos expresan los planes nacionales, regionales y locales elaborados dentro de las líneas generales del plan de desarrollo económico y social de la Nación, aprobadas por la asamblea nacional, en aquellos aspectos que exigen por parte del sector público captar y asignar recursos contundentes al cumplimiento de metas de desarrollo económico social e institucional del país.

La Ley Orgánica de Administración Financiera del Sector Publico (2006) incorporó, entre otros aspectos: 
- La elaboración de los presupuestos plurianuales.

- La creación de la Oficina Nacional de Presupuesto, (ONAPRE) que viene a sustituir la Oficina Central de Presupuesto (OCEPRE).

En relación al régimen legal presupuestario, es importante señalar otra normativa que contiene una serie de principios que deben regir la gestión fiscal de los entes del sector público, como lo es la Ley Orgánica de la Administración Pública (LOAP, 2008), en su artículo 1, el cual tiene por objeto establecer principios y bases que rigen la organización y funcionamiento de la administración pública, los principios y lineamientos de la organización y funcionamiento de la administración pública nacional y de la administración descentralizada funcionalmente; así como regular los compromisos de gestión, crear mecanismos para promover la participación y control sobre las políticas y resultados públicos; y establecer las normas básicas sobre los archivos y registros públicos.

De igual manera en su artículo 16, se establece que:

Para la creación de órganos y entes administrativos se sujetará a los siguientes requisitos... Previsión de las partidas y créditos presupuestarios necesarios para su funcionamiento. En las correspondientes leyes de presupuesto se establecerán partidas destinadas al financiamiento de las reformas organizativas que se programen en los órganos y entes de la Administración Pública.

En su artículo 17, por su parte, establece el principio de la responsabilidad fiscal cuando expresamente señala:

No podrán crearse nuevos órganos o entes en la Administración Pública que impliquen un aumento en el gasto recurrente de la República, los estados, los distritos metropolitanos o de los municipios, sin que se creen o prevean nuevas fuentes de ingresos ordinarios de igual o mayor magnitud a la necesaria para permitir su funcionamiento.

Del mismo tenor, para dar cumplimiento a lo pautado en el artículo 187 de la LOAFSP, que enuncia: “...La administración pública antes del 31 de diciembre del año 2002 ajustara sus estructuras y procedimientos a las disposiciones de esta ley". Asimismo, el ejecutivo nacional dictara los reglamentos necesarios, antes del 15 de marzo de 2001, fue aprobado el Reglamento $\mathrm{N}^{\circ} 1$ de la Ley Orgánica de la Administración Financiera del Sector Publico (2001), con el objeto establecer normas complementarias para el desarrollo del proceso presupuestario que cumplirán los órganos y entes sujetos a la Ley Orgánica de la Administración Financiera del Sector Publico.

- Reforma Parcial del Reglamento No 1 de la Ley Orgánica de Administración Financiera del Sector Publico sobre el Sistema Presupuestario (2002), en el cual se destaca un nuevo capítulo que se agrega al citado reglamento, concerniente a la liquidación y cierre del presupuesto de la república. 
Eduardo J. Millano
500 Historia y actualidad del Régimen Legal del Sistema Presupuestario Público Venezolano

- Reforma Parcial del Reglamento $\mathrm{N}^{\circ} 1$ de la Ley Orgánica de la Administración Financiera del Sector Publico sobre el Sistema Presupuestario (2005), el cual se aprobó con el objeto de desarrollar los aspectos inherentes a la nueva técnica de elaboración del presupuesto por proyectos y acciones centralizadas.

Es importante señalar que las disposiciones en materia presupuestaria, aplicables al estado, puede regir a los estados, al Distrito Metropolitano de Caracas, los distritos y municipios, toda vez que la Constitución de la República Bolivariana de Venezuela (1999) establece que los principios y disposiciones establecidas para la administración económica y financiera nacional regularan la de los estados y municipios en cuanto sean aplicables (art. 311).

A tenor de lo antes expuesto, se puede afirmar que el proceso presupuestario de los estados, distritos y municipios se regirá por las leyes estadales, la Ley Orgánica del Poder Público Municipal y las ordenanzas municipales respectivas, pero se ajustaran en cuanto sea posible a las disposiciones técnicas que establezca la Oficina Nacional de Presupuesto. A estos fines, las disposiciones que dicten estas entidades en esta materia deberán ajustarse a los principios constitucionales y a los establecidos en la Ley Orgánica de Administración Financiera del Sector Publico para su ejecución y desarrollo (arts.62 y 64 LOAFSP).

Del análisis de las leyes anteriormente citadas, se desprende que las actividades que realizan los órganos y entes que integran el sector público, relacionadas con el manejo del patrimonio de la nación y de las finanzas públicas en general, están regidas por numerosas normativas que armonizan unas con otras, a fin de lograr la ejecución de una gestión fiscal que deberá estar basada en los principios de eficiencia, solvencia, transparencia, responsabilidad y equilibrio fiscal, tal como lo contempla la carta magna.

Ahora bien, lo que respecta al el presupuesto de la nación dejó de pasar por el control político administrativo de la asamblea nacional desde 2016, un hecho que marcó el quiebre de la democracia como forma de gobierno de la república violando el precepto constitucional como lo es el artículo 187 de la Constitución vigente establece que es atribución del Poder Legislativo "discutir y aprobar el presupuesto nacional y todo 
proyecto de ley concerniente al régimen tributario y al crédito público". ${ }^{2}$ El mismo fue aprobado en el año 2016, 2017 y 2018 por el Tribunal Supremo de Justicia en vista de que el ejecutivo nacional no cuenta con una mayoría adepta a sus ideales político y por tanto con una mayoría opositora, recurriendo al órgano de justicia el cual no es competente para la evaluación, discusión, sanción y aprobación de instrumento jurídico contable. Todo esto fue sostenido por la teoría del desacato de la asamblea nacional que entro en funciones en el año $2015^{3}$

Para la fecha que se escribe este trabajo (Presupuesto anual del 2019) el presupuesto de la nación fue discutido y aprobado por la Asamblea Nacional Constituyente, convocada en fecha 1 de mayo de 2017 por el presidente de la república, la cual fue cuestionada por la mayoría política opositora del país. La misma no es reconocida por una gran cantidad de estados y no goza de legitimidad suficiente. Para finalizar se debe acotar lo que respecta a las fases de aprobación de las leyes, las cuales no se han cumplido porque este último para la fecha de la investigación, aún no se había publicado en gaceta oficial y sus partidas no son conocidas, por tanto, se concluye que su fases para la elaboración y estimación no fueron estudiadas así como preparadas por expertos en la materia, causando incertidumbre en el soberano y reflejando transparencia en los proceso de recaudación de recursos y egresos del estado.

2 La constitución de la República Bolivariana de Venezuela desarrolla un título completo en relación con el Sistema Presupuestario:

Artículo 311. La gestión fiscal estará regida y será ejecutada con base en principios de eficiencia, solvencia, transparencia, responsabilidad y equilibrio fiscal. Esta debe equilibrarse en el marco plurianual del presupuesto, de manera que los ingresos ordinarios deben ser suficientes para cubrir los gastos ordinarios.

El Ejecutivo Nacional presentará a la Asamblea Nacional para su sanción legal un marco plurianual para la formulación presupuestaria que establezca los límites máximos de gasto y endeudamiento que hayan de contemplarse en los presupuestos nacionales. La ley establecerá las características de este marco, los requisitos para su modificación y los términos de su cumplimiento.

El ingreso que se genere por la explotación de la riqueza del subsuelo y los minerales, en general, propenderá a financiar la inversión real productiva, la educación y la salud.

Los principios y disposiciones establecidas para la administración económica y financiera nacional regularán la de los Estados y Municipios en cuanto sean aplicables.

Artículo 312 “...La ley especial indicará las modalidades de las operaciones y autorizará los créditos presupuestarios correspondientes en la respectiva ley de presupuesto.”

Artículo 313. "La administración económica y financiera del Estado se regirá por un presupuesto aprobado anualmente por ley. El Ejecutivo Nacional presentará a la Asamblea Nacional, en la oportunidad que señale la ley orgánica, el proyecto de Ley de Presupuesto. Si el Poder Ejecutivo, por cualquier causa, no hubiese presentado a la Asamblea Nacional el proyecto de ley de presupuesto dentro del plazo establecido legalmente, o el mismo fuera rechazado por éste, seguirá vigente el presupuesto del ejercicio fiscal en curso..."

Artículo 314. "No se hará ningún tipo de gasto que no haya sido previsto en la ley de presupuesto..."

Artículo 315. ..." El Poder Ejecutivo, dentro de los seis meses posteriores al vencimiento del ejercicio anual, presentará a la Asamblea Nacional la rendición de cuentas y el balance de la ejecución presupuestaria correspondiente a dicho ejercicio."

3 Véase Sentencia en relación disponible en línea: http://historico.tsj.gob.ve/decisiones/scon/ octubre/190792-814-111016-2016-2016-897.HTML 
Eduardo J. Millano
$5 \mathrm{O}$ Historia y actualidad del Régimen Legal del Sistema Presupuestario Público Venezolano

\section{Conclusiones}

El estudio del sistema presupuestario, comprende una gran labor histórica, dogmática así como legal para estudiosos de las ciencias económicas, jurídico financieras y contables, por cuanto el mismo, es el instrumento mediante el cual el estado estructura, proyecta sus ingresos y gastos de manera anual, el mismo es formulado por el ejecutivo nacional con asesoría de su órgano ministerial como lo es el ministerio de finanzas, respectivamente debe pasar de acuerdo a lo indicado en la constitución por el órgano legislativo como lo es en el caso venezolano la asamblea nacional. En este paseo histórico normativo se pudo ver su evolución legislativa con relación a la importancia que, para el desarrollo de la nación, para precisar aspectos relevantes en la organización de la ley y sobre la construcción en Venezuela del derecho presupuestario, como tal.

Sin embargo, se enfatiza que Venezuela debe promover mayor estudio en las disciplinas financieras para culturizar a la sociedad en temas de derecho financiero y presupuestario, con el fin de evitar los abusos de poder e interponer los recursos jurídicos para no transgredir los principios constitucionales y democráticos de la sociedad venezolana establecidos en los referidos sistemas de la nación.

\section{Referencias bibliográficas}

ANDARA, Lenin. 2012. El Presupuesto Público Venezolano. Editado por el Concejo de Publicaciones de la Universidades de los Andes. Mérida, Venezuela.

ASAMBLEA NACIONAL. 200o. Reglamento No. 1 de la Ley Orgánica De la Administración Financiera del sector público sobre el sistema presupuestario (2001, diciembre 8) Gaceta Oficial De la República Bolivariana de Venezuela. No 37. 348 diciembre 18. 2000. Caracas, Venezuela.

ASAMBLEA NACIONAL. 2002. Reglamento No. 3 de la Ley Orgánica de la Administración Financiera del sector público, sobre el sistema de tesorería (2002, marzo 22) Gaceta Oficial De la República Bolivariana De Venezuela. No. 37. 419 abril 9, 2002. Caracas, Venezuela.

ASAMBLEA NACIONAL. 2005. Reglamento No. 2 de la Ley Orgánica De la Administración Financiera del sector público sobre el sistema de crédito público (2005, enero 17) Gaceta Oficial de la República Bolivariana de Venezuela. Caracas, Venezuela. 
ASAMBLEA NACIONAL. 2007. Ley Orgánica De la Administración Financiera del Sector Público. Gaceta Oficial De la República Bolivariana De Venezuela. No 38. 661 abril 11. Caracas, Venezuela.

ASAMBLEA NACIONAL. Ley Orgánica de la Contraloría General de la República y del Sistema Nacional de Control Fiscal. Gaceta Oficial $\mathrm{N}^{\circ}$ 37.347 de fecha 17 de diciembre de 2001. Caracas, Venezuela.

ASAMBLEA NACIONAL. Reforma Parcial de la ley Orgánica de administración financiera del sector público (2007, marzo 11) Gaceta Oficial De la República Bolivariana De Venezuela. No. 38.648 marzo 20, 2007. Caracas, Venezuela.

ASAMBLEA NACIONAL. Reforma Parcial de la Ley Orgánica de la Administración Financiera del Sector Publico (2011, agosto 23) Gaceta Oficial De la República Bolivariana de Venezuela. No. 39.741 AGOSTO 23, 2011. Caracas, Venezuela.

ASAMBLEA NACIONAL. Reforma parcial del reglamento No. 1 de la ley Orgánica de la Administración Financiera Del sector Publico sobre el sistema presupuestario (2002 junio 26) Gaceta Oficial De la República Bolivariana De Venezuela. Decreto No. 1.835. Caracas, Venezuela.

ASAMBLEA NACIONAL. Reglamento de la ley Orgánica de la Contraloría General De la República y Sistema Nacional De control Fiscal (2001, marzo 27) Decreto No. 1263. Gaceta Oficial De la República Bolivariana De Venezuela. No. 37. 4.169 marzo 29, 2001. Caracas, Venezuela.

ASAMBLEA NACIONAL. Reglamento No. 4 De la ley Orgánica de la administración Financiera del sector público, sobre el sistema de contabilidad pública (2002, diciembre 28) Gaceta Oficial de La República Bolivariana De Venezuela. No. 5. 623 diciembre 28, 2002. Caracas, Venezuela.

CABRERA, Elery. 1988. Historia de la Contraloría General de la República. Tomo I y II. Caracas, Venezuela.

CHALBAUD, Reinaldo 1999 Estado y Política. Derecho constitucional e instituciones políticas. Sexta edición. Ediciones Líber. Caracas, Venezuela.

CONGRESO DE LA REPÚBLICA DE VENEZUELA. 1976. Ley Orgánica de Régimen Presupuestario. (1976, Julio 30). Con reforma de 1980. Gaceta Oficial $N^{\circ}$ 2.712. Extraordinaria de fecha 30-12-1980. Caracas, Venezuela.

CONGRESO DE LA REPÚBLICA DE VENEZUELA. Ley Orgánica De la Hacienda Pública Nacional (1974, junio 11) Gaceta Oficial De Venezuela No. 1.660 extraordinario julio 21, 1974). Caracas, Venezuela. 
DIAZ, Jazmin; ANNICCHARICO Elvira; MARIN Vanessa. 2006. "Actualidad Contable” En: Faces. Vol. 9, No. 13, julio-diciembre, pp. 30-41.

DUVERGER, Maurice. 1980. La Hacienda Pública. Editorial Bosch. Barcelona, España.

ESTEVES, José. 2005. Diccionario razonado de economía. Editorial Panapo. Caracas, Venezuela.

FARIÑAS, Guillermo. 1986. Temas de Finanzas Públicas, Derecho Tributario. Editorial UCV. Caracas, Venezuela.

PAREDES, Fabricio 2011. El Presupuesto Público Aspectos Teóricos-Prácticos. Universidad de los Andes. Mérida, Venezuela.

RACHADELL, Manuel 1993. Lecciones Sobre el presupuesto Público. Editorial jurídica venezolana. Caracas, Venezuela.

RODRÍGUEZ, Luisa. 2014. Actividad Financiera del Sector Público en Venezuela. Editado por la Universidad de Carabobo. Valencia, Venezuela.

VILLEGAS, Héctor. 1975. Curso de Finanzas, Derecho Financiero y Derecho Tributario. Editorial palma. Buenos Aires, Argentina. 

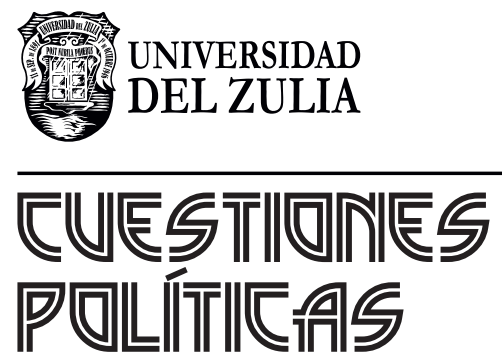

Vol.39 No 68

Esta revista fue editada en formato digital y publicada en enero de 2021, por el Fondo Editorial Serbiluz, Universidad del Zulia. Maracaibo-Venezuela 